\title{
Educational and behavioral interventions for asthma: who achieves which outcomes? A systematic review
}

This article was published in the following Dove Press journal:

Journal of Asthma and Allergy

9 December 2010

Number of times this article has been viewed

\author{
Noreen M Clark' \\ Christopher Griffiths ${ }^{2}$ \\ Stephanie R Keteyian' \\ Martyn R Partridge ${ }^{3}$ \\ 'Center for Managing Chronic \\ Disease, University of Michigan, \\ Ann Arbor, MI, USA; 'Primary Care, \\ Queen Mary's School of Medicine \\ and Dentistry, Barts and the London \\ Centre for General Practice \\ and Primary Care, London, UK; \\ ${ }^{3}$ Department of Respiratory Medicine, \\ Imperial College London, London, UK
}

Correspondence: Noreen M Clark Myron E.Wegman Distinguished University Professor Director, Center for Managing Chronic Disease, University of Michigan, 14I 5 Washington Heights, Ann Arbor, MI 48109-2029, USA

Tel + | 734763 |457

Fax +I 7347639115

Emailnmclark@umich.edu
Objectives: Randomized clinical trial (RCT) data reviewed for outcomes and processes associated with asthma educational and behavioral interventions provided by different types of health professionals.

Methods: Cochrane Collaboration, MEDLINE, PUBMED, Google Scholar search from 1998 to 2009 identified 1650 articles regarding asthma educational and behavioral interventions resulting in 249 potential studies and following assessment produced a final sample of 50 RCTs.

Results: Approaches, intended outcomes, and program providers vary greatly. No rationale provided in study reports for the selection of specific outcomes, program providers, or program components. Health care utilization and symptom control have been the most common outcomes assessed. Specific providers favor particular teaching approaches. Multidisciplinary teams have been the most frequent providers of asthma interventions. Physician-led interventions were most successful for outcomes related to the use of health care. Multidisciplinary teams were best in achieving symptom reduction and quality of life. Lay persons were best in achieving self-management/self-efficacy outcomes. Components most frequently employed in successful programs are skills to improve patient-clinician communication and education to enhance patient self-management. Fifty percent of interventions achieved reduction in the use of health care and one-third in symptom control. A combination approach including self-management and patient-clinician communication involving multidisciplinary team members may have the greatest effect on most outcomes.

Conclusions: The extent to which and how different providers achieve asthma outcomes through educational and behavioral interventions is emerging from recent studies. Health care use and symptom control are evolving as the gold standard for intervention outcomes. Development of self-management and clinician-patient communication skills are program components associated with success across outcomes and providers.

Keywords: interventions, asthma, health professionals, systematic review

\section{Introduction}

Nonpharmacological interventions to support children and adults with asthma include self-management education and support, information giving, behavioral change techniques, and efforts to enhance communication between the person with asthma and health care professionals. These diverse interventions have been provided by an equally diverse range of individuals from physicians to nurses, multidisciplinary teams, pharmacists, and lay educators. Evaluation in these trials has utilized a variety of outcome measures. This review set out to determine the type of interventions offered by various professionals and what type of outcomes they achieve. 
In the past decade, the quality and quantity of asthma educational and behavioral interventions have increased, probably as a result of high asthma prevalence, advances in the understanding of clinical management and management by patients, and increasing interest in theories of education and behavior change. ${ }^{1-3}$ Educational and behavioral programs evaluated in clinical trials have been delivered by a variety of health professionals and lay people. Rigorously evaluated interventions have aimed at achieving a variety of outcomes and have used a variety of program components.

The financial and material costs of delivering interventions for asthma, although not always discussed in reports of findings, can be expected to differ, at least, according to whose time must be covered to implement the program. Theoretically, different types of program providers may differ in their ability to produce desired outcomes. For example, it may be that clinicians could be expected to be more able to address correct use of medical regimens and lay persons more able to advise regarding day-to-day barriers to managing asthma effectively. However, such assumptions have not been tested empirically.

This review of interventions aimed at (a) describing the outcomes of clinical trials of asthma educational and behavioral interventions undertaken by different types of providers in the past decade and $(b)$ exploring differences in program components employed by them.

\section{Methods}

Articles appearing in the English language in the Cochrane Collaboration Data Base, MEDLINE, PUBMED, and Google Scholar were searched. Reference lists on identified articles were also searched. Search terms included asthma self-management, asthma behavior, asthma randomized controlled trials, asthma outcomes, asthma education, and asthma patient education. Inclusion criteria were publication in a peer-reviewed journal between 1990 and 2009; randomized clinical trial (RCT) to assess an educational or behavioral intervention for asthma; and evidence of statistical assessment of asthma-related outcomes on at least one variable including asthma symptoms, pulmonary function, medicine use, psychosocial factors, days absent from work or school, days of restricted activity due to asthma, selfmanagement, self-efficacy, quality of life, emergency department use, hospital in-patient stays, and office visits. Success in achieving outcomes was accepted as statistical difference between interventions and control in a patient sample of at least 100 subjects. Virtually no study provided sample size calculations, and as asthma outcomes related to health care use generally require larger samples, 100 was considered a generous cut point. Studies failing to meet all of these criteria were excluded.

The initial search was broad, accepting any article related to evaluation of social and behavioral interventions to ensure a comprehensive view of available work, and generated 1650 articles. Preliminary application of study criteria identified 249 potential studies for inclusion that met one or more criteria. Further review of these investigations by two independent reviewers yielded 50 RCTs that fully met all inclusion criteria. No individual authors were contacted for information. No further review of methodological quality of the studies was conducted beyond that it appeared in a peer review journal and comprised an RCT. The 50 eligible articles were again closely examined by two individuals and data extracted using a standard protocol regarding target population, sample size, program provider, program content, intervention components, processes, and outcomes. Comparison among provider type was computation of differences between percent of successful program to number attempted. No further statistical analyses were employed.

\section{Results}

The majority of the $50 \mathrm{RCT}$ evaluated programs were conducted by teams of providers $(n=20)$ and the least by pharmacists $(n=4)$. Just above $28 \%$ were offered to adults with asthma, just under $65 \%$ were for children, and $7 \%$ included both.

Table 1 illustrates that among the most frequently studied outcomes (health care use, symptoms, self-management/ self-efficacy, and quality of life), health care use was the outcome most frequently reported. In the majority of studies, no delineation was made as to which were primary versus secondary goals of the research. A number of studies described more than one outcome resulting from the program, and not all reported about the same or included all the major outcomes. Table 2 provides the outcomes achieved in programs by provider type. Considering the number of interventions undertaken by type of provider and the number reporting success achieving health care use reductions, physicians had a $83 \%$ success rate (ie, the percent of times positive health care reduction outcomes were reported given the number of studies by that type of provider), nurses reported success in $73 \%$ of their undertakings, pharmacists reported no success, multidisciplinary teams reported $50 \%$ success, and lay people $35 \%$ success. For reports of symptom reduction, reported success for physicians was 33\%, nurses $36 \%$, pharmacists $50 \%$, multidisciplinary teams $51 \%$, and lay 
Table I Studies by provider and major outcomes (symptoms, health care use, quality of life, self-management/self-efficacy)

\begin{tabular}{|c|c|c|c|}
\hline Health care use & Symptom reduction & Quality of life & $\begin{array}{l}\text { Self-management/ } \\
\text { self-efficacy }\end{array}$ \\
\hline \multicolumn{4}{|l|}{ Physicians (programs $n=5$ ) } \\
\hline Cabana et $\mathrm{al}^{4}$ & Glasgow et $\mathrm{al}^{6}$ & - & - \\
\hline Clark et $\mathrm{al}^{5}$ & Yoon et al ${ }^{9}$ & - & - \\
\hline Glasgow et $\mathrm{al}^{6 *}$ & - & - & - \\
\hline Hoskins et $\mathrm{al}^{7}$ & - & - & - \\
\hline Moudgil et $\mathrm{a}^{8}$ & - & - & - \\
\hline \multicolumn{4}{|l|}{ Nurses (programs $n=12$ ) } \\
\hline Bolton et al ${ }^{10}$ & Becker et al ${ }^{18}$ & Abdulwadud et $\mathrm{al}^{20}$ & - \\
\hline Charlton et al" & Clark et $\mathrm{al}^{13}$ & Cleland et $\mathrm{a}^{21}$ & - \\
\hline Choy et al ${ }^{12}$ & Levy et al ${ }^{14}$ & - & - \\
\hline Clark et $\mathrm{al}^{13}$ & Madge et $\mathrm{a}^{15}$ & - & - \\
\hline Levy et $\mathrm{al}^{14}$ & Wilson et al ${ }^{19 *}$ & - & - \\
\hline Madge et al ${ }^{15}$ & - & - & - \\
\hline Webber et $\mathrm{al}^{16}$ & - & - & - \\
\hline Wesseldine et $\mathrm{al}^{17}$ & - & - & - \\
\hline \multicolumn{4}{|l|}{ Pharmacists (programs $n=4$ ) } \\
\hline Weinberger et $\mathrm{a}^{22}$ (increased) & Armour et $\mathrm{al}^{23}$ & Stergachis et $\mathrm{al}^{25 *}$ & - \\
\hline P & Barbonel et al ${ }^{58}$ & - & - \\
\hline \multicolumn{4}{|c|}{ Teams of providers (programs $n=20$ ) } \\
\hline Butz et $\mathrm{al}^{26}$ & Bruzzese et $\mathrm{al}^{36}$ & Butz et $\mathrm{a}^{26}$ & Chiang et $\mathrm{a}^{27}$ \\
\hline Chiang et $\mathrm{al}^{27}$ & Cano-Garcinuno et $\mathrm{al}^{37}$ & Krieger et al ${ }^{30}$ & Clark et al ${ }^{38}$ \\
\hline Ghosh et $\mathrm{al}^{28 *}$ & Clark et $\mathrm{a}^{38}$ & Lahdensuo et $\mathrm{a}^{31}$ & Griffiths et $\mathrm{al}^{44}$ \\
\hline Glasgow et $a^{6 *}$ & Garrett et $\mathrm{al}^{39}$ & Magar et al $\left.\right|^{40}$ & - \\
\hline Karnick et $\mathrm{al}^{29}$ & Griffiths et $\mathrm{al}^{44}$ & Shames et $\mathrm{al}^{43}$ & - \\
\hline Krieger et $\mathrm{a}^{30}$ & Krieger et $\mathrm{al}^{30}$ & - & - \\
\hline Lahdensuo et $\mathrm{al}^{31}$ & Magar et $\mathrm{al}^{40}$ & - & - \\
\hline Robinson et $\mathrm{a}^{32}$ & MeGhan et al ${ }^{41}$ & - & - \\
\hline Splett et $\mathrm{al}^{33}$ & Sullivan et al ${ }^{42}$ & - & - \\
\hline Walders et $\mathrm{al}^{34}$ & Yoon et $\mathrm{al}^{9}$ & - & - \\
\hline Zeiger et $\mathrm{al}^{35}$ & Zeiger et $\mathrm{a}^{35}$ & - & - \\
\hline \multicolumn{4}{|l|}{ Lay person (programs $n=9$ ) } \\
\hline Adams et $\mathrm{al}^{45}$ & Canino et $\mathrm{al}^{48}$ & Henry et $\mathrm{al}^{49}$ & Bonner et $\mathrm{a}^{51}$ \\
\hline Bryant-Stephens and $\mathrm{Li}^{46}$ & - & Shah et al ${ }^{50}$ & Griffiths et $\mathrm{al}^{24}$ \\
\hline Partridge et $\mathrm{al}^{47}$ & - & - & Turner et $\mathrm{a}^{52}$ \\
\hline \multicolumn{4}{|c|}{ (outcomes compared against nurses) } \\
\hline Total $n=28$ & 21 & 10 & 6 \\
\hline
\end{tabular}

Note: *No significant results.

people $11 \%$. Multidisciplinary teams reported achieving quality of life outcomes in 50\% of the studied programs and lay persons' self-management and/or self-efficacy outcomes in $33 \%$ of programs.

Auxiliary outcomes of a more mediating or psychosocial type beyond the most frequently reported major outcomes were described in some studies. Table 3 presents these other outcomes. The most frequently reported outcome of a mediating or psychosocial type was use of medicines and delivery devices. Team-provided programs reported these results most often.

Table 4 presents the components and processes of the interventions by provider type and outcome. Program approaches varied from providing highly specific asthma information along with specialist consultations, for example,
Levy et al, ${ }^{14}$ to enhancing patient-clinician interactions including emphasis on communication, for example, Cabana et al, ${ }^{4}$ to paying indirect attention to asthma in literacy education, for example, Robinson et al. ${ }^{32}$

Table 5 presents program focus, content, and processes by outcome. Clinician-patient communication, self-management skills, control of the environment, and medicine and device use were all employed in programs that reduced health care use. Action plans, peak expiratory flow (PEF) monitoring, control of the environment, and clinician-patient communication skills were employed in interventions that reduced asthma symptoms. Patient-clinician communication and patient asthma self-management education were included in interventions improving quality of life and self-management outcomes. Two areas of focus, interactions between patients 
Table 2 Which provider group reported major outcomes and percent success*

\begin{tabular}{lllll}
\hline & $\begin{array}{l}\text { Success in health } \\
\text { care use }\end{array}$ & $\begin{array}{l}\text { Success in symptom } \\
\text { reduction }\end{array}$ & $\begin{array}{l}\text { Success in } \\
\text { quality of life }\end{array}$ & $\begin{array}{l}\text { Success in self-management/ } \\
\text { self-efficacy }\end{array}$ \\
\hline Physician-led programs $(n=5)$ & $83 \%(n=5)$ & $33 \%(n=2)$ & - & - \\
Nurse $(n=12)$ & $73 \%(n=8)$ & $36 \%(n=4)$ & $20 \%(n=2)$ & - \\
Pharmacist $(n=4)$ & - & $50 \%(n=2)$ & - & - \\
Teams $(n=20)$ & $50 \%(n=10)$ & $55 \%(n=11)$ & $25 \%(n=5)$ & $15 \%(n=3)$ \\
Lay person $(n=9)$ & $33 \%(n=3)$ & $11 \%(n=1)$ & $2 \%(n=2)$ & $33 \%(n=3)$ \\
\hline
\end{tabular}

Notes: *Percent of successful outcomes in number of programs by profession.

and clinicians and patient education for self-management, were evident in all interventions reporting major outcomes, that is, those related to health care use, symptoms, selfmanagement/self-efficacy, or quality of life.

Table 6 presents activities most used by different types of program providers. Physician-directed programs emphasized one-on-one counseling, self-monitoring, and use of diaries/action plans. Nurses used individual, group, and telephone learning sessions and employed activities to elicit patient participation such as role plays and problem-solving exercises. They also engaged in home visiting. Teams used a range of these activities and, in addition, case managers. Lay people-led programs involved individual, group, and home visit sessions and use of peer educators. Pharmacists used one-on-one counseling.

\section{Discussion and conclusion}

Findings from this review of asthma interventions demonstrate that several types of providers have led programs assessed through RCTs using various program components and reporting varying results. No one common outcome has been sought by all the available studies. No rationale was provided in research reports for why given program planners sought to emphasize certain outcomes and not others or included certain program components and not others or deployed certain program providers and not others.

There is a degree of consistency in outcomes achieved across the interventions as measured by frequency of reports of reaching a category of major outcome. Almost half of the interventions achieved reductions in health care use and about one-third reduced frequencies of asthma symptoms. Proportionately, physician-led programs mostly reported health care use improvements.

This review suggests that there is an evolving gold standard for asthma interventions. So many have demonstrated symptom or health care use improvements that these may have become the unofficial bench mark of success. This review also suggests that clinician-patient communication and patient self-management may be the most promising to include in efforts to change health care use and reduce asthma symptoms as these elements have been included in all programs to date reporting such outcomes.

A number of studies have described only outcomes related to self-efficacy, medicine use, school/work absenteeism, feelings about asthma, etc. Each of these clearly can be important outcomes for patients. Some, in fact, may be the mediating factors producing what we have termed major outcomes. The frequency with which these auxiliary results have been sought and achieved has been less than attempts to achieve change in symptoms, health care use, selfmanagement/self-efficacy, and quality of life. These more distal outcomes have likely been assumed by program planners to be associated with major outcomes. However, their connection has not, as yet, been empirically demonstrated in intervention research. In other words, support for these being the sole outcome sought and achieved in interventions, until they are proven to be the route to clinical changes, is questionable.

Important considerations regarding the type of program leader and interventions themselves could not be addressed in this exploration. For example, the relative costs of delivering a program and the cost of training different types of individuals to lead programs differ. Physician time is usually expensive whether providing an intervention solo or as part of a team. Teams may cost more than a nurse delivering a program alone. Peer leaders may be the least expensive in implementation but not in training and needed backup support. A program with many components may be the most powerful or as this study suggests one or two very effective elements may produce the best results. Knowing program costs and savings is important in choosing types of interventions.

Several limitations to this description of interventions are apparent. The number of studies in each provider category was uneven and often very small. For example, many trials involving teams have been conducted, while only four concern pharmacists. Exclusion of studies of fewer than 100 subjects may have worked against some studies where 


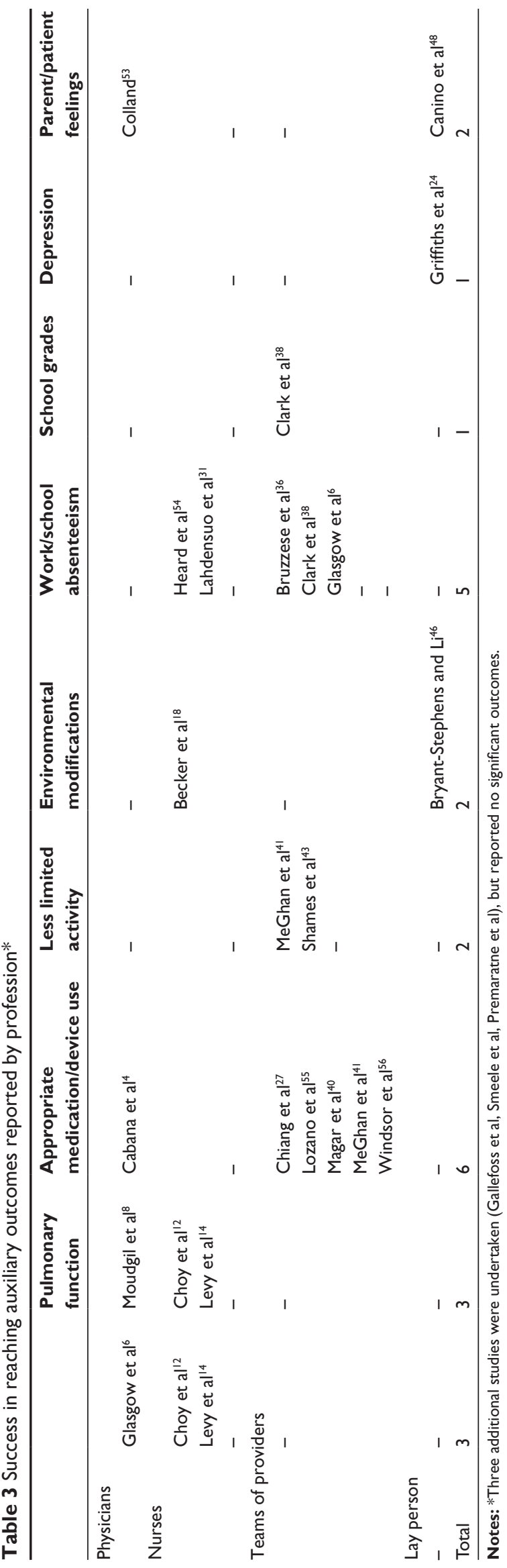

sample size recalculation would indicate smaller numbers could ascertain differences. Studies of teams of providers did not describe fully the relative roles of team members or assess which provider had the most influence on success. No multifactorial research designs were used in the studies included here to uncover which element or combination of elements in the intervention produced the outcome. Reports of only five negative studies could be located. The publication of negative studies in the literature is quite rare. Thus, our findings may be subject to publication bias. In one study, for example, Griffiths et $\mathrm{al}^{24}$ not all patients had asthma and the whole may not reflect subgroup differences. A few studies focused on specific ethnic/racial groups (eg, African-American, Chinese, South Asian), but no comparison between approaches for differing ethnicities was available. As components of interventions may have differing effects on subgroups of the population, comparative effective studies appear needed. Further, investigations in this review comprise those targeted at children, at adults, and sometimes both. The relative advantages of approaches identified here for younger and older patients were not clear in the available data and deserve attention in future studies.

How, by necessity, we have looked at the extant studies that also reflect weaknesses in the field more generally. For example, measures used to assess asthma outcomes are not standard and/or are not applied in a standard way. The rationale and/or theory underlying the components of an intervention were not described in study reports inhibiting theoretical conclusions regarding why an intervention may or may not have worked. Descriptions of the organizational context for program delivery, or success in institutionalizing an effective intervention, were not presented, so characteristics of sustainability or longevity of programs cannot be assessed. Nonetheless, the findings from this review are instructive concerning the current situation regarding the type of providers and components of interventions apparently associated with specific asthma outcomes.

A number of recommendations are evident in the results of this review. One, as noted, is the need for standard asthma outcome measures and uniform application of them. New efforts by the US National Heart, Lung, and Blood Institute and a joint Committee of the European Respiratory Association and American Thoracic Society to identify and assess the validity and reliability of asthma outcome measures should help in this regard. ${ }^{60}$ Another is to consider health care use and symptom reduction as the gold standards of intervention success. If programs do not, at minimum, achieve these results, their added value and a strong rationale for their 


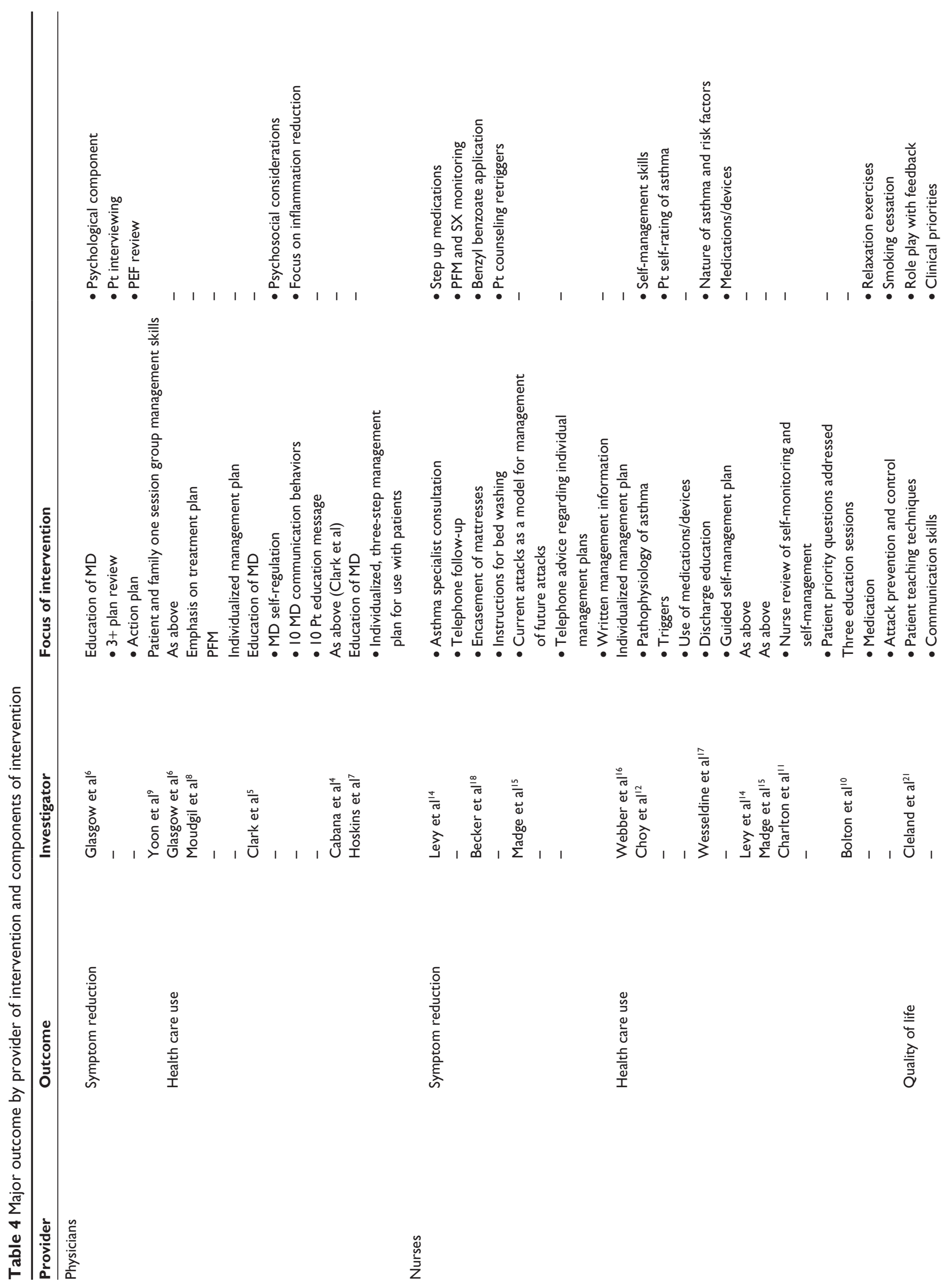




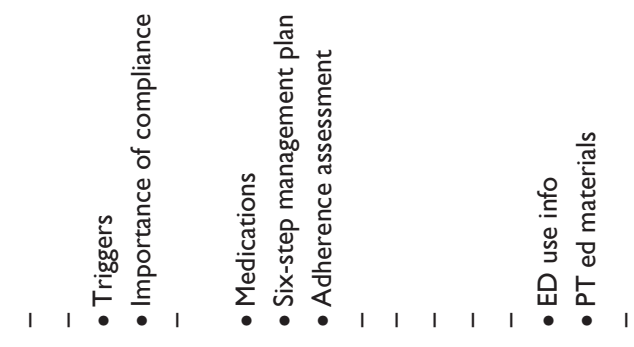

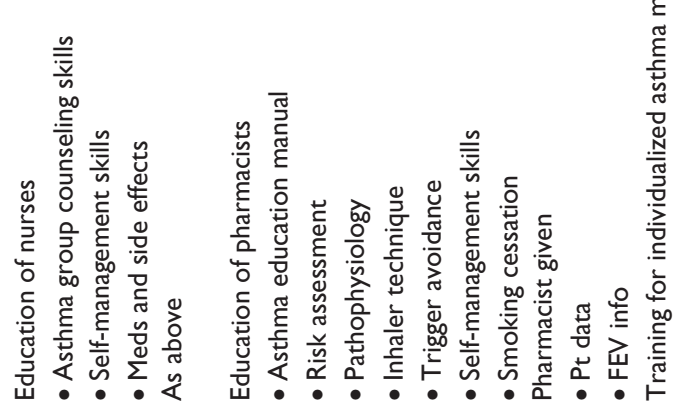
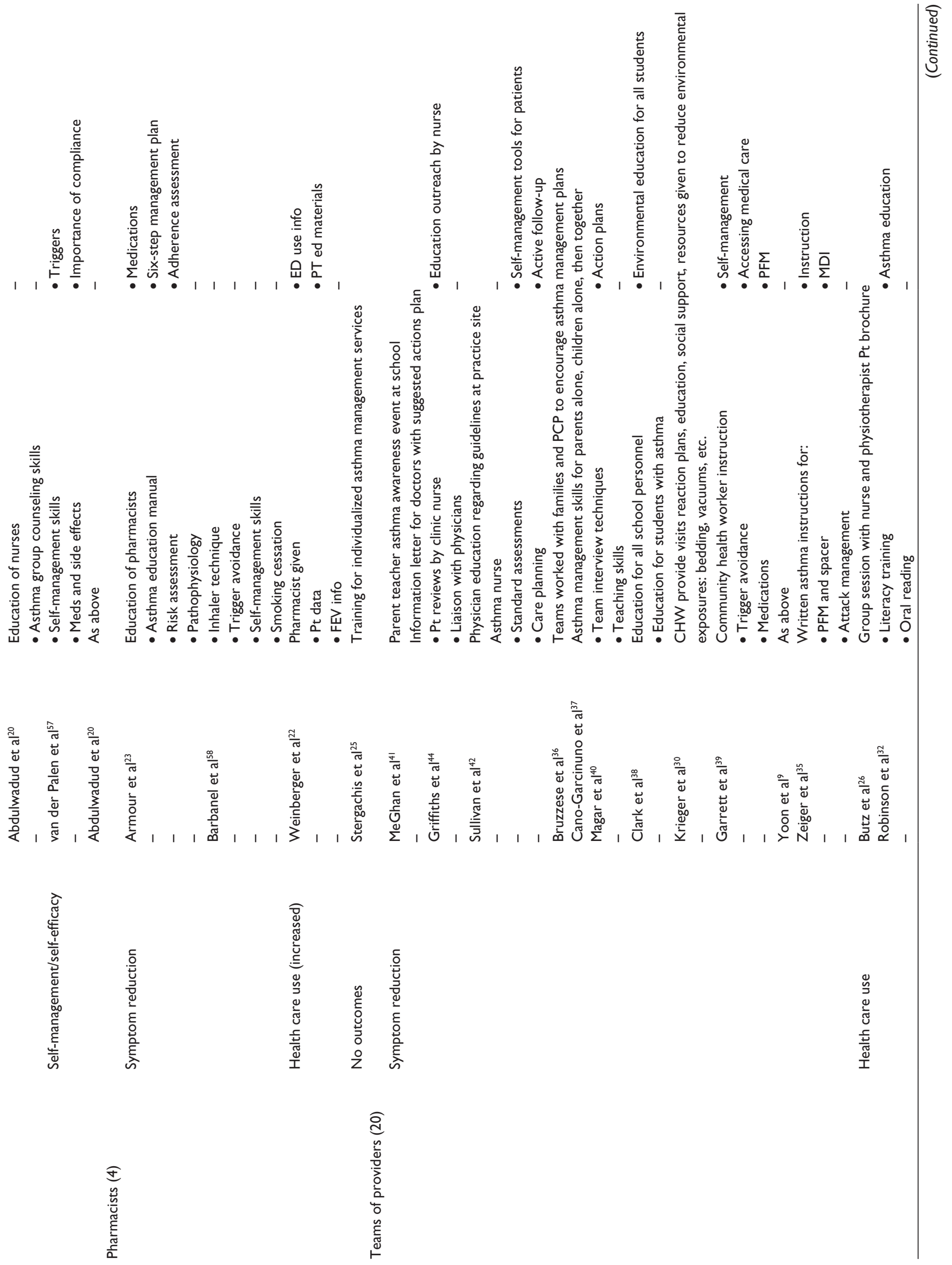


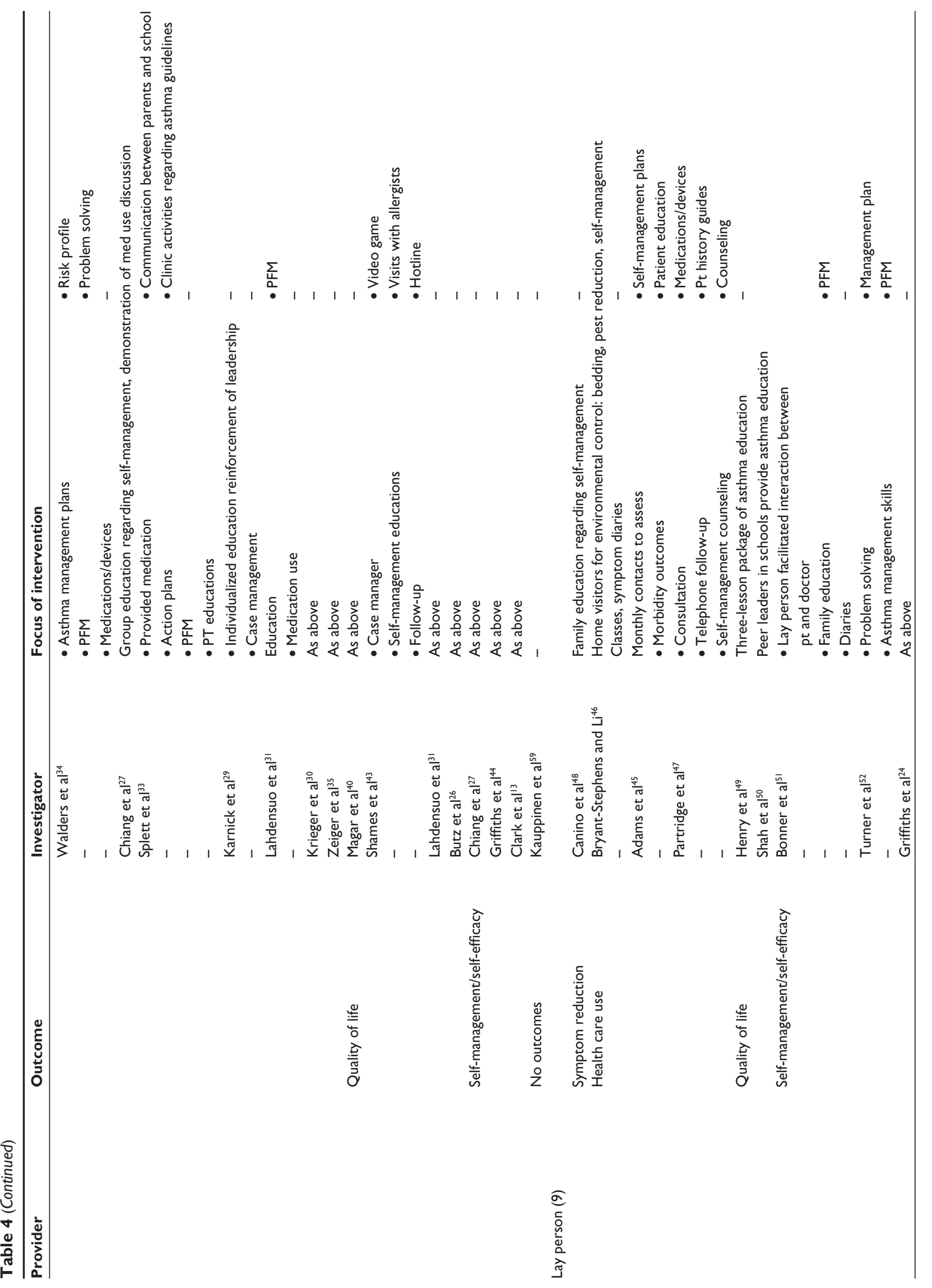


Table 5 Most common intervention elements by outcome

\begin{tabular}{llcc}
\hline Health care use & Symptoms & Quality of life & Self-management \\
\hline - Patient-clinician communication & $\bullet$ Patient-clinician & $\bullet$ Patient-clinician & communication \\
- Patient education regarding & communication & $\bullet$ Patient education regarding & - Patient education regarding \\
self-management & - Action plans & asthma management & \\
- Environment control/modification & - PEF monitoring & anvironment & \\
techniques/materials & control/modification & \\
- Use of medications/devices/action & & \\
Plans & & \\
\hline
\end{tabular}

association with clinical or quality of life improvements would appear to be needed. Also needed as part of standard practice in program planning is a clearer rationale for selection of a) intended outcomes b) program provider selected to pursue the outcomes, and c) the program components included to achieve it.

Specific intervention studies are needed that evaluate the comparative effectiveness of programs as provided by one type of health professional versus another. The only

Table 6 Teaching/learning approaches most used by provider

\begin{tabular}{|c|c|}
\hline Provider & Teaching/learning approaches \\
\hline \multicolumn{2}{|l|}{ Physicians } \\
\hline & Individualized sessions with patients one-on-on \\
\hline & Self-monitoring/regulation \\
\hline & Patient diaries/action plans \\
\hline \multicolumn{2}{|l|}{ Nurses } \\
\hline & Group and individual patient education session \\
\hline & Role plays \\
\hline & Problem solving \\
\hline & Home visits for environment control and pt \\
\hline & education \\
\hline & Patient diaries \\
\hline & Telephone counseling \\
\hline \multicolumn{2}{|c|}{ Pharmacists } \\
\hline & Patient assessment \\
\hline & $\begin{array}{l}\text { Individual pt medication monitoring and } \\
\text { counseling }\end{array}$ \\
\hline \multicolumn{2}{|c|}{ Teams of providers } \\
\hline & Groups and individual pt educational sessions \\
\hline & face-to-face \\
\hline & Information for patient physician \\
\hline & Peer educators \\
\hline & Telephone consultation \\
\hline & Web-based team discussion \\
\hline & Telephone advice line \\
\hline & Case managers \\
\hline & $\begin{array}{l}\text { Home visits for environmental control and } \\
\text { pt education }\end{array}$ \\
\hline
\end{tabular}

Lay person

Groups and individual patient educations sessions

Home visits for environmental control and pt education

Peer educators such study identified in this review was one by Partridge et al, ${ }^{47}$ where lay providers were compared to nurse program providers. The relative advantage of different providers appears to have important implications for both the type of outcomes achieved and the frequency of achieving them, as well as, cost of program implementation. An implication of these findings is that those with a specific professional background may benefit from adopting the techniques successfully used by other professionals. Multifactorial studies are needed to compare program components for their relative effectiveness in producing outcomes. Needed personnel, supervision, as well as, intensity and duration evident in the interventions studied varied greatly. Research is needed to examine the costs of program delivery against the savings generated by outcomes. Cost pressures in most health care systems make acquisition of this information necessary to ensure adoption and institutionalization of interventions that can assist patients to reduce the burden of asthma on them, their families, and their communities.

\section{Conclusion}

In the past decade, multidisciplinary teams have been the most frequent providers of asthma educational and behavioral interventions. Health care use and symptom reduction have been the most frequent outcomes of interventions. Physician-led programs have most reported health care use reductions. Teams have most reported symptom reductions. Two elements, self-management skills and physician-patient communication, have been the program components most deployed by providers successfully reaching these outcomes. Costs have not been assessed. Apparent emerging gold standards for asthma interventions are outcomes related to reductions in symptoms and/or health care use. Outcomes produced by different program components and different providers vary with some having more success with clinically related results and some with more potentially mediating psychosocial-related results. Comparative effectiveness studies are needed to assess outcomes associated with different program providers and program components. 


\section{Acknowledgment}

The study presented here was supported by grant \# R 01 HL60884 from the Lung Division of the National Heart, Lung, and Blood Institute of the National Institutes of Health.

\section{Disclosure}

The authors report no conflicts of interest in this work.

\section{References}

1. British Thoracic Society. British guidelines on the management of asthma: a national clinical guideline. Thorax. 2008;63 Suppl IV:iv1-iv121.

2. National Asthma Education and Prevention Program. Expert panel report 3: guidelines for the diagnosis and management of asthma. National Heart, Lung and Blood Institute; 2007 Aug 28. Report No: 3.

3. Noar SM, Chabot M, Zimmerman RS. Applying health behavior theory to multiple behavior change: considerations and approaches. Prev Med. 2008;46(3):275-280.

4. Cabana MD, Slish KK, Evans D, et al. Impact of physician asthma care education on patient outcomes. Pediatrics. 2006;117(6):2149-2157.

5. Clark NM, Gong M, Schork MA, et al. Long-term effects of asthma education for physicians on patient satisfaction and use of health services. Eur Respir J. 2000;16(1):15-21.

6. Glasgow NJ, Ponsonby AL, Yates R, Beilby J, Dugdale P. Proactive asthma care in childhood: general practice based randomized controlled trial. BMJ. 2003;327(7416):659.

7. Hoskins G, Neville RG, Smith B, Clark RA. Do self-management plans reduce morbidity in patients with asthma? Br J Gen Pract. 1996; 46(404):169-171.

8. Moudgil H, Marshall T, Honeybourne D. Asthma education and quality of life in the community: a randomised controlled study to evaluate the impact on white European and Indian subcontinent ethnic groups from socioeconomically deprived areas in Birmingham, UK. Thorax. 2000; 55(3): 177-183.

9. Yoon R, McKenzie DK, Bauman A, Miles DA. Controlled trial evaluation of an asthma education programme for adults. Thorax. 1993;48(11): 1110-1116.

10. Bolton MB, Tilley BC, Kuder J, Reeves T, Schultz LR. The cost and effectiveness of an education program for adults who have asthma. J Gen Intern Med. 1991;6(5):401-407.

11. Charlton I, Charlton G, Broomfield J, Mullee MA. Evaluation of peak flow and symptoms only self management plans for control of asthma in general practice. BMJ. 1990;301(6765):1355-1359.

12. Choy DK, Tong M, Ko F, et al. Evaluation of the efficacy of a hospitalbased asthma education programme in patients of low socioeconomic status in Hong Kong. Clin Exp Allergy. 1999;29(1):84-90.

13. Clark NM, Gong ZM, Wang SJ, Lin X, Bria WF, Johnson TR. A randomized trial of a self-regulation intervention for women with asthma. Chest. 2007;132(1):88-97.

14. Levy ML, Robb M, Allen J, Doherty C, Bland JM, Winter RJ. A randomized controlled evaluation of specialist nurse education following accident and emergency department attendance for acute asthma. Respir Med. 2000;94(9):900-908.

15. Madge P, McColl J, Paton J. Impact of a nurse-led home management training programme in children admitted to hospital with acute asthma: a randomised controlled study. Thorax. 1997;52(3):223-228.

16. Webber MP, Hoxie AM, Odlum M, Oruwariye T, Lo Y, Appel D. Impact of asthma intervention in two elementary school-based health centers in the Bronx, New York City. Pediatr Pulmonol. 2005;40(6):487-493.

17. Wesseldine LJ, McCarthy P, Silverman M. Structured discharge procedure for children admitted to hospital with acute asthma: a randomised controlled trial of nursing practice. Arch Dis Child. 1999;80(2): $110-114$.
18. Becker A, Watson W, Ferguson A, Dimich-Ward H, Chan-Yeung M. The Canadian asthma primary prevention study: outcomes at 2 years of age. J Allergy Clin Immunol. 2004;113(4):650-656.

19. Wilson SR, Scamagas P, German DF, et al. A controlled trial of two forms of self-management education for adults with asthma. Am J Med. 1993;94(6):564-576.

20. Abdulwadud O, Abramson M, Forbes A, James A, Walters E. Evaluation of a randomized controlled trial of adult asthma education in a hospital setting. Thorax. 1999;54(6):493-500.

21. Cleland JA, Hall S, Price D, Lee AJ. An exploratory, pragmatic, cluster randomised trial of practice nurse training in the use of asthma action plans. Prim Care Respir J. 2007;16(5):311-318.

22. Weinberger M, Murray MD, Marrero DG, et al. Effectiveness of pharmacist care for patients with reactive airways disease: a randomized controlled trial. JAMA. 2002;288(13):1594-1602.

23. Armour C, Bosnic-Anticevich S, Brillant M, et al. Pharmacy Asthma Care Program (PACP) improves outcomes for patients in the community. Thorax. 2007;62(6):496-502.

24. Griffiths C, Motlib J, Azad A, et al. Randomised controlled trial of a lay-led self-management programme for Bangladeshi patients with chronic disease. Br J Gen Pract. 2005;55(520):831-837.

25. Stergachis A, Gardner JS, Anderson MT, Sullivan SD. Improving pediatric asthma outcomes in the community setting: does pharmaceutical care make a difference? J Am Pharm Assoc (Wash). 2002;42(5): 743-752.

26. Butz A, Pham L, Lewis L, et al. Rural children with asthma: impact of a parent and child asthma education program. J Asthma. 2005;42(10): 813-821.

27. Chiang LC, Huang JL, Yeh KW, Lu CM. Effects of a self-management asthma educational program in Taiwan based on PRECEDE-PROCEED model for parents with asthmatic children. J Asthma. 2004;41(2): 205-215.

28. Ghosh CS, Ravindran P, Joshi M, Stearns SC. Reductions in hospital use from self management training for chronic asthmatics. Soc Sci Med. 1998;46(8):1087-1093.

29. Karnick P, Margellos-Anast H, Seals G, Whitman S, Aljadeff G, Johnson D. The pediatric asthma intervention: a comprehensive costeffective approach to asthma management in a disadvantaged inner-city community. J Asthma. 2007;44(1):39-44.

30. Krieger JW, Takaro TK, Song L, Weaver M. The Seattle-King County Healthy Homes Project: a randomized, controlled trial of a community health worker intervention to decrease exposure to indoor asthma triggers. Am J Public Health. 2005;95(4):652-659.

31. Lahdensuo A, Haahtela T, Herrala J, et al. Randomised comparison of guided self management and traditional treatment of asthma over one year. $B M J .1996 ; 312(7033): 748-752$.

32. Robinson LD Jr, Calmes DP, Bazargan M. The impact of literacy enhancement on asthma-related outcomes among underserved children. J Natl Med Assoc. 2008;100(8):892-896.

33. Splett PL, Erickson CD, Belseth SB, Jensen C. Evaluation and sustainability of the healthy learners asthma initiative. J Sch Health. 2006; 76(6):276-282.

34. Walders N, Kercsmar C, Schluchter M, Redline S, Kirchner HL, Drotar D. An interdisciplinary intervention for under treated pediatric asthma. Chest. 2006;129(2):292-299.

35. Zeiger RS, Heller S, Mellon MH, Wald J, Falkoff R, Schatz M. Facilitated referral to asthma specialist reduces relapses in asthma emergency room visits. J Allergy Clin Immunol. 1991;87(6):1160-1168.

36. Bruzzese JM, Evans D, Wiesemann S, et al. Using school staff to establish a preventive network of care to improve elementary school students' control of asthma. $J$ Sch Health. 2006;76(6):307-312.

37. Cano-Garcinuno A, Diaz-Vazquez C, Carvajal-Uruena I, PraenaCrespo M, Gatti-Vinoly A, Garcia-Guerra I. Group education on asthma for children and caregivers: a randomized, controlled trial addressing effects on morbidity and quality of life. $J$ Investig Allergol Clin Immunol. 2007; 17(4):216-226. 
38. Clark NM, Brown R, Joseph CL, Anderson EW, Liu M, Valerio MA. Effects of a comprehensive school-based asthma program on symptoms, parent management, grades, and absenteeism. Chest. 2004;125(5): 1674-1679.

39. Garrett J, Fenwick JM, Taylor G, Mitchell E, Stewart J, Rea H. Prospective controlled evaluation of the effect of a community based asthma education centre in a multiracial working class neighbourhood. Thorax. 1994;49(10):976-983.

40. Magar Y, Vervloet D, Steenhouwer F, et al. Assessment of a therapeutic education programme for asthma patients: 'un souffle nouveau'. Patient Educ Couns. 2005;58(1):41-46.

41. MeGhan SL, Wong E, Jhangri GS, et al. Evaluation of an education program for elementary school children with asthma. J Asthma. 2003; 40(5):523-533.

42. Sullivan SD, Lee TA, Blough DK, et al. A multisite randomized trial of the effects of physician education and organizational change in chronic asthma care: cost-effectiveness analysis of the Pediatric Asthma Care Patient Outcomes Research Team II (PAC-PORT II). Arch Pediatr Adolesc Med. 2005;159(5):428-434.

43. Shames RS, Sharek P, Mayer M, et al. Effectiveness of a multicomponent self-management program in at-risk, school-aged children with asthma. Ann Allergy Asthma Immunol. 2004;92(6):611-618.

44. Griffiths C, Foster G, Barnes N, et al. Specialist nurse intervention to reduce unscheduled asthma care in a deprived multiethnic area: the east London randomised controlled trial for high risk asthma (ELECTRA). BMJ. 2004;328(7432):144.

45. Adams RJ, Boath K, Homan S, Campbell DA, Ruffin RE. A randomized trial of peak-flow and symptom-based action plans in adults with moderate-to-severe asthma. Respirology. 2001;6(4):297-304.

46. Bryant-Stephens T, Li Y. Outcomes of a home-based environmental remediation for urban children with asthma. J Natl Med Assoc. 2008; 100(3):306-316.

47. Partridge MR, Caress AL, Brown C, et al. Can lay people deliver asthma self-management education as effectively as primary care based practice nurses? Thorax. 2008;63(9):778-783.

48. Canino G, Vila D, Normand SL. Reducing asthma health disparities in poor Puerto Rican children: the effectiveness of a culturally tailored family intervention. J Allergy Clin Immunol. 2008;121(3):665-670.

49. Henry RL, Gibson PG, Vimpani GV, Francis JL, Hazell J. Randomized controlled trial of a teacher-led asthma education program. Pediatr Pulmonol. 2004;38(6):434-442.

50. Shah S, Peat JK, Mazurski EJ, et al. Effect of peer led programme for asthma education in adolescents: cluster randomised controlled trial. BMJ. 2001;322(7286):583-585.
51. Bonner S, Zimmerman BJ, Evans D, Irigoyen M, Resnick D, Mellins RB. An individualized intervention to improve asthma management among urban Latino and African-American families. J Asthma. 2002;39(2):167-179.

52. Turner S, Eastwood P, Cook A, Jenkins S. Improvements in symptoms and quality of life following exercise training in older adults with moderate/ severe persistent asthma. Respiration. 2010. [Epub ahead of print].

53. Colland VT. Learning to cope with asthma: a behavioural selfmanagement program for children. Patient Educ Couns. 1993;22(3): $141-152$.

54. Heard AR, Richards IJ, Alpers JH, Pilotto LS, Smith BJ, Black JA. Randomised controlled trial of general practice based asthma clinics. Med J Aust. 1999;171(2):68-71.

55. Lozano P, Finkelstein JA, Carey VJ, et al. A multisite randomized trial of the effects of physician education and organizational change in chronic-asthma care: health outcomes of the Pediatric Asthma Care Patient Outcomes Research Team II Study. Arch Pediatr Adolesc Med. 2004;158(9):875-883.

56. Windsor RA, Bailey WC, Richards JM Jr, Manzella B, Soong SJ, Brooks M. Evaluation of the efficacy and cost effectiveness of health education methods to increase medication adherence among adults with asthma. Am J Public Health. 1990;80(12):1519-1521.

57. van der Palen J, Klein JJ, Zielhuis GA, van Herwaarden CL, Seydel ER. Behavioural effect of self-treatment guidelines in a self-management program for adults with asthma. Patient Educ Couns. 2001;43(2): $161-169$.

58. Barbanel D, Eldridge S, Griffiths C. Can a self-management programme delivered by a community pharmacist improve asthma control? A randomised trial. Thorax. 2003;58(10):851-854.

59. Kauppinen R, Sintonen H, Tukiainen H. One-year economic evaluation of intensive vs. conventional patient education and supervision for self-management of new asthmatic patients. Respir Med. 1998;92(2): 300-307.

60. American Thoracic Society and European Respiratory Society Task Force on Asthma Control and Exacerbations. An official American Thoracic Society/European Respiratory Society statement: asthma control and exacerbations: standardizing endpoints for clinical asthma trials and clinical practice. Am J Respir Crit Care Med. 2009;180(1): 59-99
Journal of Asthma and Allergy

\section{Publish your work in this journal}

The Journal of Asthma and Allergy is an international, peer-reviewed open-access journal publishing original research, reports, editorials and commentaries on the following topics: Asthma; Pulmonary physiology; Asthma related clinical health; Clinical immunology and the immunological basis of disease; Pharmacological interventions and

\section{Dovepress}

new therapies. Issues of patient safety and quality of care will also be considered. The manuscript management system is completely online and includes a very quick and fair peer-review system, which is all easy to use. Visit http://www.dovepress.com/testimonials.php to read real quotes from published authors. 